Health \& Medicine | R. Anbazhagan, M. Dufau \& K. Raghuveer

\title{
Male infertility and the genesis of mature sperm cells
}

About $10 \%$ of all males in the United States who are attempting to conceive suffer from infertility. Dr Rajakumar Anbazhagan, Dr Maria L. Dufau and Dr Kavarthapu Raghuveer from the National Institutes of Health, USA, aim to understand the biochemical pathways behind male factor infertility to devise a proin known as goreds tropin-reguted testicular RNA helicase (GRTH), which plays a fundamental role in the maturation of sperm cells.

\section{ore than 5 million couples in
the US alone have trouble
cocevin \\ $\checkmark$ conceiving. Male factor}

infertility cases. There are many causes contributing to male infertility: the sperm produced by infertile men may be immature, abnormally shaped, or unable to move through fluid media. In some cases, there is not enough sperm or no
sperm at all. Dr Rajakumar Anbazhagan

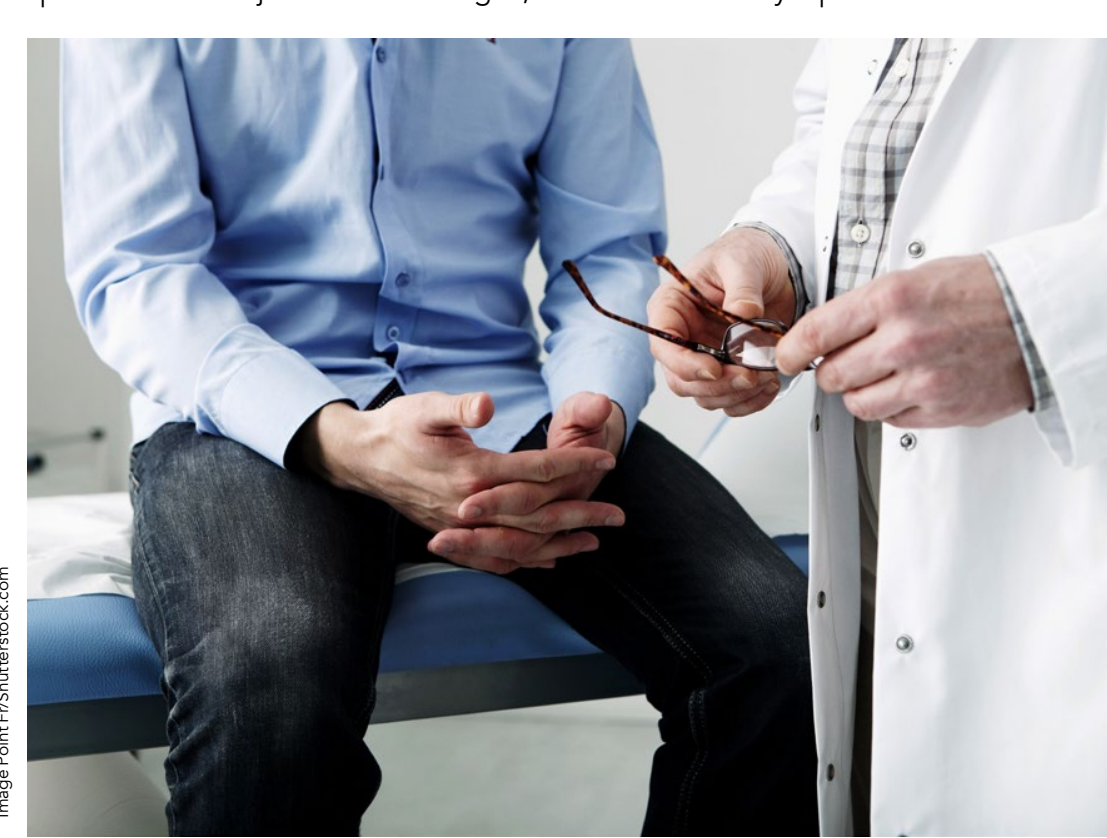

gonadotropin-regulated testicular RNA helicase $(G R H)$, which carries nucleus to the cytopla) for the the progenitors of mature sperm cell. The mRNAs of germ cell genes are temporarily stored in chromatoid bodies (CB), organelles without a membrane that are found around the nucleus. During different stages of sperm formation, these mRNAs undergo translation (protein synthesis) resulting in functional sperm. The team aims to better understand the essential role played by GRTH and is interaction with CBs in the process of spermatogenesis.

THE ROLES OF GRTH AND THE CHROMATOID BODII IN SPERMATOGENESIS Germ cells contain two different forms form and the biger, non-phosphorylated version, known as phospho-GRTH. Previous work from Dr Dufau's laboratory has shown that $5.8 \%$ of a population of infertile men have a specific mutation in the gene expressing GRTH. The researchers conducted follow-up studies in cell lines and in vivo studies in mice, showing that the genetic mutation known as R242H leads to the loss of phospho-GRTH, leaving the levels of non-phosphorylated GRTH unchanged. In further studies published in 2019, transgenic (i.e., genetically modified) mice containing the $242 \mathrm{H}$ mutation were characterise which resulted in sterility and a marked which resulted in sterility and a marked to non-transgenic, wild type mice.
Furthermore, the study shows that he sterility was caused by halted the loss of viable sperm in the semen.

To better understand the mechanisms sermatogenesis, it is vital to know what $\mathrm{CBs}$ are and how they handle the processing of mRNA. CBs (RNP) organelles that dynamically equester messenger ribonucleoprotein particles (mRNPs) - mRNA bound to proteins - into compartments that are distinct from the surrounding cytoplasm. They function similarly to processing bodies (P-bodies) and stress granules of somatic cells. CBs primarily contain (SRNA), mic

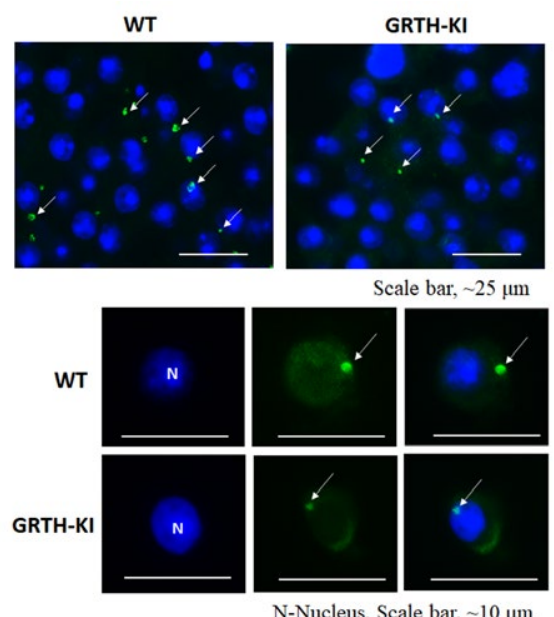
mutation (GRTHtesticular sections (top) and more rounded
spermatides (bottom compared to wild-type spermatids
mice (WT).

The team's findings demonstrate the importance of phospho-GRTH inside CB and its role in storage and stability of germ cell-specific mRNAs during healthy sperm formation.
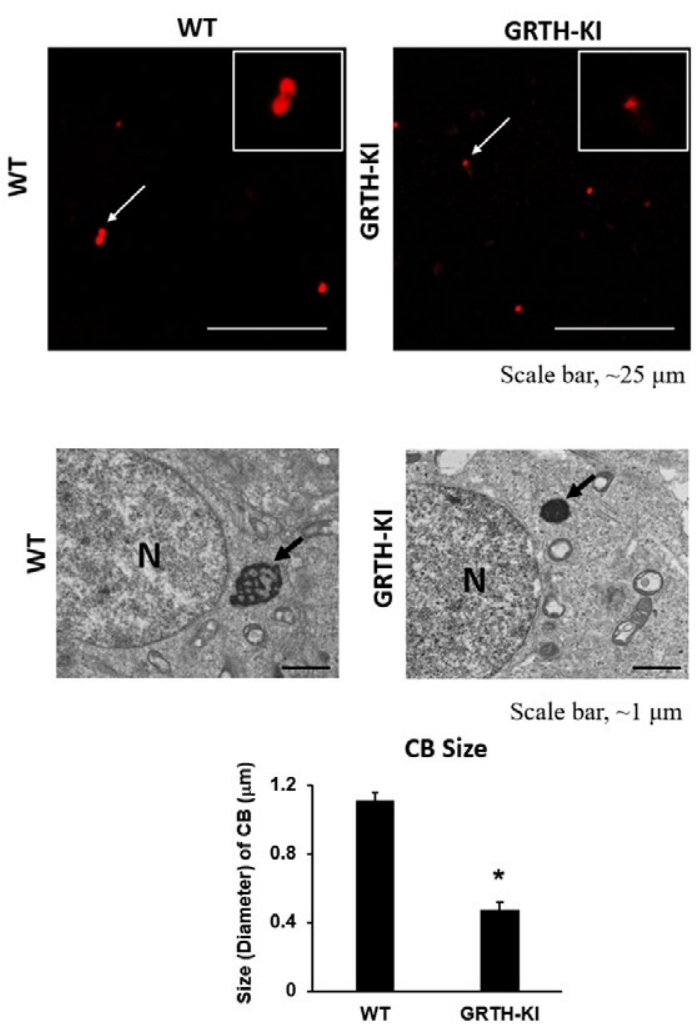

Immunofluorescence staing shows that $\mathrm{CBs}$ (red) from KI mice are smaller than WT Bottom: Electron microscopy images
from round spermatids show that CBS are clearly visible in WT,
while in KI, CBs are markedly reduced in size. proteins involved in the RNA processing as miRNA and siRNA play important roles during the post-transcriptiona stage. They control the stability of mRNA by binding to target messenger RNAs, ensuing mRNA degradation or translation inhibition. The miRNAs are expressed in a cell-specific manner during spermatogenesis to participate in the control of each step of male germ cell differentiation. miRNA silencing of chromatin remodelers proteins in round spermatids is essential for of spermiogenesis, the last step of for functionesis, which is critical for functional sperm formation. CBs temporanly store mRNAs, which are Eventually, different struch CB splits into two and the other forms a ring around the base of the flagellum of the mature sperm cell. In the 2019 \& 2020 study، Dr Anbazhagan, Dr Dufau and Dr Kavarthapu showed that phospho-GR is absent in the CBs of transgenic mice, unlike the non-phosphonglated version of the protein, which is unaffected. The
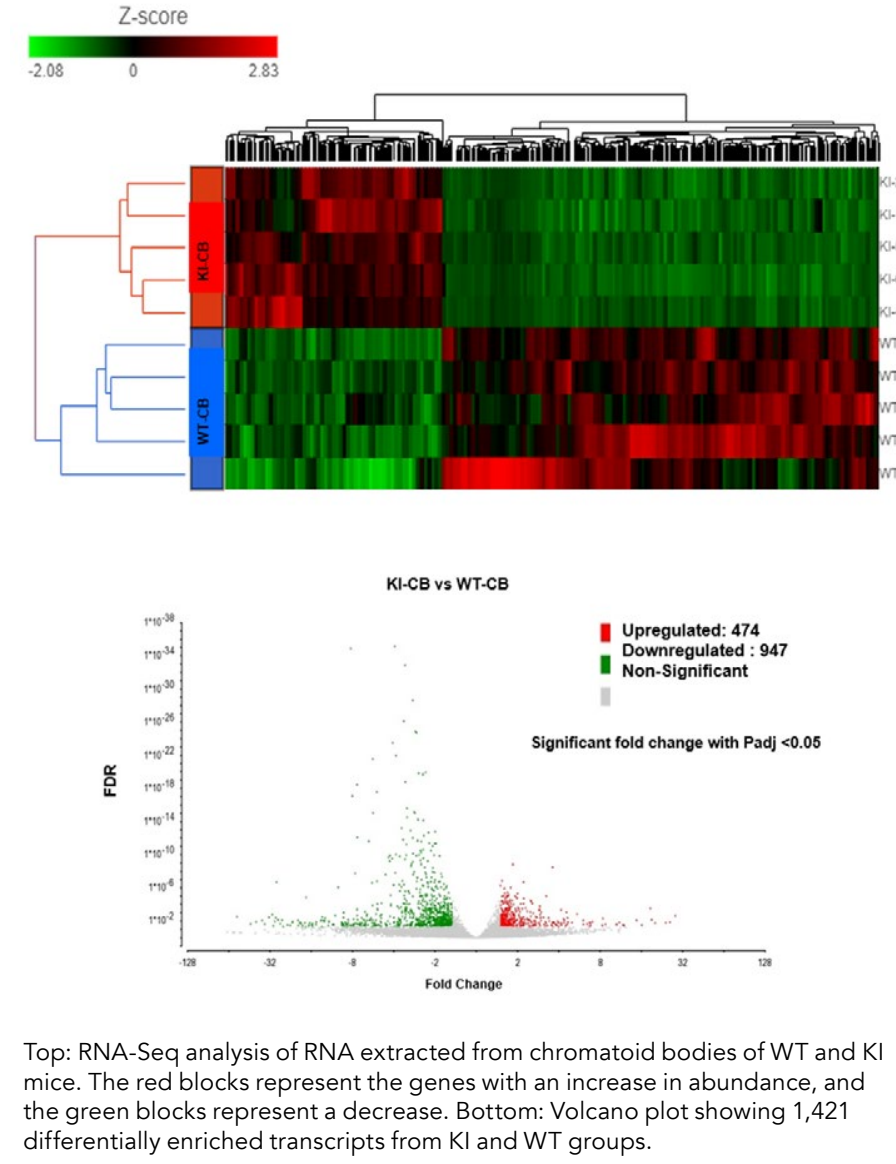

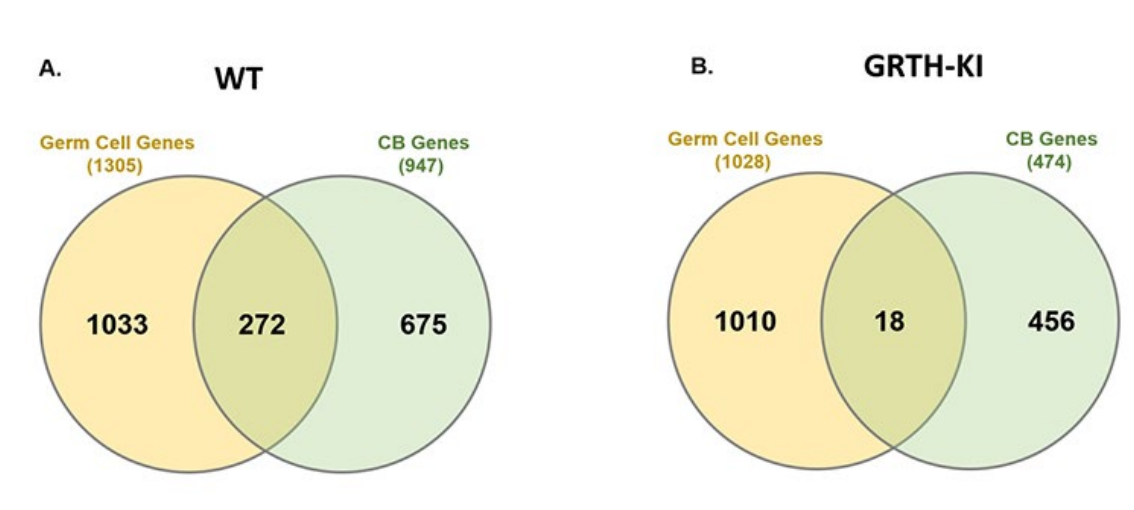

Germ cell and CB genes in WT (left) and KI (right) mice.

The studies provide convincing evidence that the lack of phosphoGRTH is the main cause of the arrest in spermatogenesis.

research team also showed a marked spermatids and lizs of essentil mand spermatids
in the CBs.

PHOSPHO-GRTH REGULATES THE STRUCTURAL AND FUNCTIONAL INTEGRITY OF CBs

In 2020, the Dufau laboratory investigated the genetic profiles of $\mathrm{CB}$ in the presence and absence of phospho-GRTH, to shed light on the biochemical pathways that are essential for the progression and completion of spermatogenesis. The study confirmed once again that transgenic mice with the R242H mutation lack the phosphorylated form of the GRTH phes the structure of $\mathrm{CBs}$.

The association of the phospho-GRTH protein with specific germ cell was decreased due to the loss of

phospho-GRTH in the CBs. Further, mRNAs could not get transported and instead, remained stored in the $\mathrm{CB}$ in transgenic mice due to loss of phospho-GRTH.

Overall, the team's findings demonstra the relevance of phospho-GRTH in the maintenance of the structure of the $\mathrm{CB}$ and its role in storage and stability of germ cell-specific mRNAs duing spermiogenesis. Due to the loss of essential proteins involved in the chromatin compaction and remodelling, the final stages of spermatogenesis are affected, resulting in halted spermatogenesis. These processes GRTH in the inpol tance of phosphoof sperm cells and fertility.

One of the main findings of the lab's recent studies was that the loss of
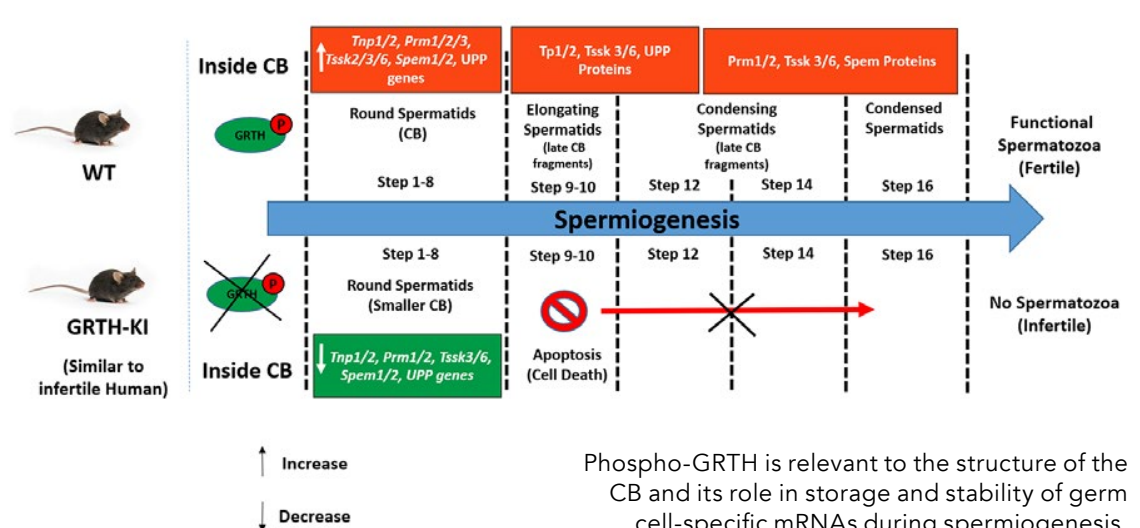

CB and its role in storage and stability of germ
cell-specific mRNAs during spermiogenesis. ransgenic mice resulted in sterility with he total lack of sperm and elongated reduction in several germ cell specific gene transcripts in the $\mathrm{CBs}$ of the transgenic mice. The researchers argued that this decrease in germ cell mRNAs likely results from mRNA degradation due to the absence of phosphoGRTH in CB. The altered sequence of molecular events eventually leads to the failure of chromatin remodelling, which is needed for the correct chromosoma organisation of mature sperm cells. Thus, the studies provide convincing evidence that the lack of phosphoin spermatogenesis.

PHOSPHO-GRTH IS ESSENTIAL FOR SPERMATID DEVELOPMENT AND COMPLETION OF SPERMIOGENESIS The 2020 study highlights the essential in the play by phosphorylated GRTH modification during spermiogenesis. Histones such as $\mathrm{H} 2 \mathrm{~A}, \mathrm{H} 2 \mathrm{~B}, \mathrm{H} 3$, and $\mathrm{H} 4$ are proteins involved in the correct packaging and assembly of genetic material. The absence of phospho-GRTH impairs the enzymatic ubiquitination and acetylation of histones, probably because of a considerable reduction in the ubiquitination-related genes in the CBs of transgenic mice. In addition there is a complete loss of TP2 and PRM2 proteins. These chromatin remodelling proteins play a crucial role reshaping the nuclonsef eltion and eshaping the nucleus of elongating disruption of these processes results in the complete impairment of spermatid development in transgenic mice lackin phospho-GRTH, which causes them to be sterile. The findings led the researchers to formulate the hypothesis that the phosphorylation of GRTH might act as a switch for spermatogenesis. Importantly, this could be used in the development of non-hormonal male contraceptives.

The studies carried out by $D$ Anbazhagan, Dr Raghuveer and Dr Dufau provided first evidence of cell-specific regulation of GRTH and resulting in functional sprage in CBs, and fertility.

\section{Behind the Research}

ब

Dr Rajakumar

Anbazhagan

E: rajianbazhagan@nih.gov

T: +1 1 3014962171
W: orcid.org/0000-0001-7643-4479

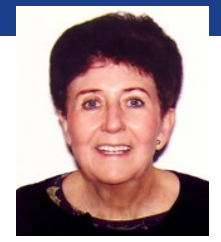

Dr Maria L.

Dufau

E: dufaum@mail.nih.gov

T: raghu.kavarthapu@nih.gov

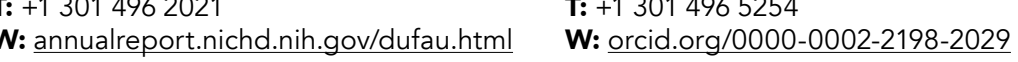

Dr Kavarthapu

Raghuveer

Research Objectives

The researchers study spermatogenesis in order to better understand male infertility.

\section{Detail}

9000 Rockville Pike
Building 6/Room 1 A05 National Institutes of Health (NIH) Bethesda, Maryland-20892

Dr Rajakumar Anbazhagan is a visiting fellow at the Section of Endocrinology MSc (Biochemistry \& Molecular Biolog) and PhD in Animal Sciences (Molecular Endocrinology). Dr Anbazhagan's

expertise includes
promoter regu

promoter regulation of gene expression,
epigenetics, and NGS analysis. Current

research is focused on post-transcription

control (mRNA and small RNAs) and the

P-bodies) during spermiogenesis.

\section{References}

Anbazhagan, R, Kavarthapu, R, Coon, S L, Dufau, M L, Testicur RNA Helicase (GRTH/DDX25) in the Reguldo

of Germ Cell Specific mRNAs in Chromatoid Bodies during tiers in Cell and Development Biology 8, 580019. doi.org/10.3389/fcell.2020.580019

Kavarthapu, R, Anbazhagan, R, Sharma, A, Shiloach,
$J$, Dufau, M L, (2020) Linking phospho-Gonadotropin regulated testicular RNA helicase (GRTH/DDX25) to histone ubiquitination and acetylation essential for spermatid development during spermiogenesis. Frontiers in Cell and Development Biology 8, 310. doi.org/10.3389,

Kavarthapu, R, Anbazhagan, R, Raju, M, Morris, C T, Pickel, $J$, Dufau, M L (2019) Targeted Knock-In Mice with a Huma Mutation in GRTH/DDX25 Reveals the Essential Role of Phosphorylated GRTH in Spermatid Development during S572. do

\begin{tabular}{|c|c|}
\hline 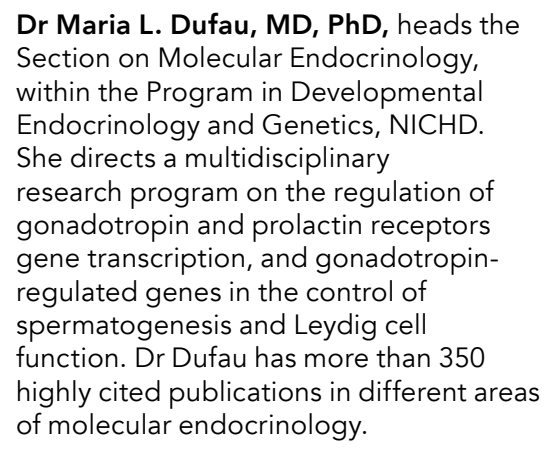 & 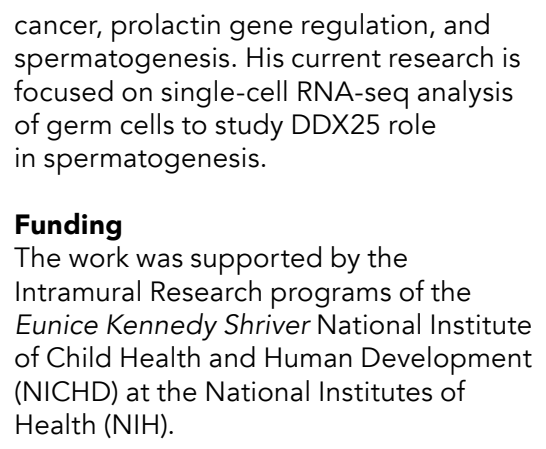 \\
\hline $\begin{array}{l}\text { Dr Kavarthapu Raghuveer is a Staff } \\
\text { Scientist at the Section of Endocrinology } \\
\text { Laboratory. He holds an MSc and } \\
\text { PhD in Animal Biotechnology. He has } \\
\text { work experience in multidisciplinary } \\
\text { areas of endocrine-related breast }\end{array}$ & $\begin{array}{l}\text { Collaborators } \\
\text { Steven L. Coon: Molecular Genomics } \\
\text { Core, Eunice Kennedy Shriver National } \\
\text { Institute of Child Health and Human } \\
\text { Development (NICHDD, National Institutes } \\
\text { of Health, Bethesda, MD 20892, USA. }\end{array}$ \\
\hline
\end{tabular}

\section{sponse}

What are the next steps of your Group's research? Whe are investigating the small RNA profiles of
chromatoid bodies and their involvement in mRNA regulation during later stages of healthy sperm. formation. Initial results are very promising.

We will also delineate the functions of different markers and molecular changes occurring at various stages of germ cells (sperm)
single-cell RNA-seq analysis.

In addition, we are studying post-transcriptional and translational control of germ cell specific gene occurring at CBs. mRNA transport from CBs to cytoplasm for
translation (protein synthesis) is providing vital clues in spermiogenesis events and molecular changes occurring in infertility. 